\title{
Impulsivity mediates the association between parenting styles and self-harm in Chinese adolescents
}

\author{
Hailiang Ran ${ }^{1}$, Die Fang ${ }^{1}$, Ahouanse Roland Donald ${ }^{1}$, Rui Wang ${ }^{2}$, Yusan Che ${ }^{1}$, Xingting He ${ }^{3}$, Tianlan Wang ${ }^{3}$,
} Xiufeng $\mathrm{Xu}^{2}$, Jin $\mathrm{Lu}^{2,4^{*}}$ and Yuanyuan Xiao ${ }^{1 *}$ (i)

\begin{abstract}
Background: Parenting styles are significantly associated with self-harm (SH) in adolescents. Nevertheless, little is known about the mechanism underlying this association. This study primarily aimed to evaluate the potential mediating role of impulsivity in the association between parenting styles and $\mathrm{SH}$ in Chinese adolescents.

Methods: Self-administered questionnaires were used to conduct a survey among a sample population consisting of 3146 adolescents in southwest China. Logistic regression analyses were performed to evaluate the association between parenting styles, impulsivity, and SH. A path model investigation further examined the mediating role of impulsivity in terms of the association between parenting styles and $\mathrm{SH}$.

Results: The age range of participants was 10 to 17 years old. The prevalence of SH was $47.0 \%$ (95\% Cl: 36.358.0\%). Impulsivity, less paternal emotional warmth, maternal over-protection, and rejection were significantly associated with $\mathrm{SH}$. The path model identified impulsivity as a salient mediator, accounting for $23.4 \%$ of the total association between parenting styles and $\mathrm{SH}$. The hypothesized path model indicated differences in the parenting styles of fathers and mothers: Impulsivity played a significant mediating role, though only in respect to the maternal over-protection and rejection paths.
\end{abstract}

Conclusions: For Chinese children and adolescents who experience a harsher maternal parenting style, impulsivitycentered intervention measures might be effective in reducing SH related to parenting styles.

Keywords: Impulsivity, Parenting styles, Self-harm, Mediation, Path analysis

\section{Background}

Self-harm (SH), which involves the direct and deliberate destruction of one's own body regardless of the intention, encompasses behaviors such as scratching or piercing the skin, self-battery, burning, etc. [1]. SH is associated with an elevated risk of various mental health problems and suicidal behaviors [2,3]. Compared with

\footnotetext{
*Correspondence: Jinlu2000@163.com; 33225647@qq.com

${ }^{2}$ Psychiatric Department, First Affiliated Hospital of Kunming Medical University, Kunming, Yunnan, China

'Department of Epidemiology and Health Statistics, School of Public Health, Kunming Medical University, Kunming, Yunnan, China

Full list of author information is available at the end of the article
}

adulthood, $\mathrm{SH}$ behavior is more common during the period of adolescence. In fact, most research studies that focused on examining the influencing factors that contribute to the occurrence, repetition, and severity of $\mathrm{SH}$ were carried out among adolescents [4]. Recently, a meta-analysis reported that the overall prevalence of $\mathrm{SH}$ was $22.4 \%$ among Chinese teenagers [5]. Individual and family negative life events, psychiatric and psychological abnormalities, and sociodemographic factors significantly increase the risk of SH in adolescents [6].

Parenting styles can be understood as a series of psychological constructs that represent standard strategies

C C The Author(s). 2021 Open Access This article is licensed under a Creative Commons Attribution 4.0 International License, which permits use, sharing, adaptation, distribution and reproduction in any medium or format, as long as you give appropriate credit to the original author(s) and the source, provide a link to the Creative Commons licence, and indicate if changes were made. The images or other third party material in this article are included in the article's Creative Commons licence, unless indicated otherwise in a credit line to the material. If material is not included in the article's Creative Commons licence and your intended use is not permitted by statutory regulation or exceeds the permitted use, you will need to obtain permission directly from the copyright holder. To view a copy of this licence, visit http://creativecommons.org/licenses/by/4.0/ The Creative Commons Public Domain Dedication waiver (http://creativecommons.org/publicdomain/zero/1.0/) applies to the data made available in this article, unless otherwise stated in a credit line to the data. 
used by parents in the child-rearing process, which generally include dimensions such as rejection, emotional warmth, and over-protection [7]. Parenting styles are extremely influential in child development. Negative parenting styles, such as rejection and neglect, can increase the risk of mental health issues in children (e.g., depression, anxiety, and hostility) and addictive behaviors [8, 9]. Furthermore, paternal and maternal parenting styles may exert different influences on the mental health and well-being of children, as suggested by recent findings [10]. Some studies revealed that negative parenting styles were also significantly related to $\mathrm{SH}$ in young people $[11,12]$. In this regard, understanding the developmental path of the association between parenting styles and $\mathrm{SH}$ is critical in order to devise intervention measures for $\mathrm{SH}$ related to parenting styles.

Impulsivity can manifest in the form of a multitude of behaviors or personality traits, including poor planning skills and persistence, and a predisposition to impulsive actions, especially in the presence of negative emotions [13]. Impulsivity is associated with many risky behaviors among adolescents, including substance and alcohol use, gambling, and unsafe sexual behaviors [14, 15]. In addition, impulsivity is regarded as a possible phenotype of SH [16]. A large body of published research studies highlighted the connection between $\mathrm{SH}$ and impulsivity, and generally concluded that individuals with a higher level of impulsivity were more likely to report SH behaviors [17]. As a personality trait, impulsivity is associated with parenting styles [18]. Furthermore, some studies demonstrated that the association between adverse childhood experiences and $\mathrm{SH}$ can be mediated by impulsivity $[19,20]$. Therefore, as negative parenting styles are, in essence, forms of adverse childhood experience, it is reasonable to theorize that impulsivity may play a mediating role in the association between such experiences and SH. However, to the best of our knowledge, this hypothesis has not been thoroughly investigated.

In the present study, we aimed to explore the association between parenting styles and $\mathrm{SH}$ using a large sample population that was representative of Chinese adolescents, and we focused on examining the theorized role of impulsivity as a mediator in regard to this association. We developed the following primary hypotheses: 1) Parenting styles are significantly associated with $\mathrm{SH}$ in Chinese adolescents; 2) Impulsivity significantly mediates this association; 3) Differences are observed in impulsivity as a mediator of the association between $\mathrm{SH}$ and paternal and maternal parenting styles.

\section{Materials and methods}

\section{Study design}

The present study was inspired by our project entitled "Epidemiological survey on mental health of school children and adolescents in Lincang city", which focused on understanding the prevalence and associated factors of mental health problems among children and adolescents in southwest China. This survey was carried out in Lingcang city, Yunnan Province, in southwest China from December 1 to December 13, 2019. Considering the representativeness of the sample, we employed a three-stage random cluster sampling strategy: In stage one, Linxiang district was randomly selected from all eight districts and counties within Lincang; in stage two, five primary schools, five junior middle high schools, and four senior middle high schools were randomly selected; finally, 3-4 classes were randomly selected from within each selected school.

Students within the selected classes were excluded if they were: 1 ) Illiterate; 2 ) suffered from a severe psychological problem(s); 3) had a physical disorder; 4) had a hearing or communication impairment; or 5) declined to participate. Furthermore, due to the fact that we assessed the presence of suicide ideation and related behavior among the participants of this study, and as it has been suggested that children aged 10 years and older can fully understand the notion of suicide [21], the following inclusion criteria were applied: 1) Aged 10 years old and above, and below 18 years old; 2) Resident in the survey area for at least 6 months per year. Ethical approval of this study was obtained from the Ethics Review Board of Kunming Medical University. Prior to the survey, both the participants and their legal guardians provided their written informed consent. Other details of study design and participants can be found in our previous publication [22].

\section{Participants}

Initially, we identified a total of 3241 adolescents from the 14 schools selected, 88 of whom were further excluded as they did not satisfy the age inclusion criterion of this study. A total of 3146 eligible adolescents were included in the final study, with an effective response rate of $97.3 \%$. For the 3146 participants: the mean age was 13.3 years, with a standard error of 0.6 ; overall, the number of male students and female students was evenly distributed (1437 versus 1709, respectively); A large proportion of the participants included those of Han ethnicity (67.1\%); the most commonly reported education level for both of the parents was "Junior high school and above" (Table 1).

\section{Measurements}

Data were collected from all participants using a selfadministered questionnaire. After participants provided their written informed consent, all participants completed the questionnaire within about $40 \mathrm{~min}$. In order to improve the quality of the survey, each questionnaire 
Table 1 General features of 3146 adolescents, Lingcang, Yunnan, China, 2019

Features

Demographic

Sex

Boys

Girls

Age (Mean (SE))

Ethnicity (\%)

Han

Other

Grade

Primary school

Junior high school

Senior high school

Socioeconomic

Father's age (Mean (SE))

Mother's age (Mean (SE))

Father's education level

Elementary school and below

Junior high school and above

Missing or unknowns

Mother's education level

Elementary school and below

Junior high school and above

Missing or Unknowns

Self-harm behavior

Yes

No

Impulsiveness (Median (IQR))

Combined score

Motor impulsiveness (Dimension 1)

Assessing impulsive planning (Dimension 2)

Cognitive impulsiveness (Dimension 3)

Degree of Impulsivity

Low (Combined score < 41.67)

High (Combined score $>=41.67$ )

Missing

Parental rearing style (Median (IQR))

Father

Rejection

Over-protection

Emotional Warmth

Mother

Rejection

Over-protection

Emotional Warmth
N (\%)

Mean (SE) / Median (IQR)

$1437(45.7)$

$1709(54.3)$

$13.32(0.60)$

$2112(67.1)$

$1034(32.9)$

$1132(36.0)$

1069 (34.0)

$945(30.0)$

$42.27(0.51)$

$39.49(0.50)$

$885(28.1)$

$1932(61.4)$

$329(10.5)$

1077 (34.2)

1816 (57.7)

253 (8.1)

1480 (47.0)

1666 (53.0)

41.67 (10.84)

30 (25)

47.5 (30)

45 (15)

1644 (52.25)

1445 (45.93)

57 (1.82)
7 (3)

16 (4)

15 (8)

8 (3)

17 (5)

$14(7)$ 
was carefully and immediately reviewed by on-site pretrained personnel who were either undergraduates recruited from a local university or postgraduates with a background of psychiatry or public health from Kunming Medical University. The structured questionnaire contained several parts which measured general characteristics, parenting styles, $\mathrm{SH}$ behaviors, impulsivity, mobile phone use, suicide ideation and behavior, resilience, depression, and anxiety. Further details regarding this questionnaire can be obtained by referring to our previous publication [22].

\section{SH behaviors}

Self-harm behaviors were defined as those outlined in the Modified version of the Adolescents Self-Harm Scale (MASHS), developed by Feng [23]. The participants were requested to answer 18 questions about the most commonly reported $\mathrm{SH}$ behaviors observed among Chinese adolescents, so as to evaluate the lifetime frequency and severity of $\mathrm{SH}$.

\section{Parenting styles}

A Chinese version of the Short-Form of the Egna Minnen Barndoms Uppfostran (S-EMBU-C) was administered to assess parenting styles during childhood years [24]. This scale measures paternal and maternal parenting styles separately by using a uniform 21 -item questionnaire. All items can be categorized into three dimensions: rejection, over-protection, and emotional warmth. The answer to each item was coded according to a four-point scale ranging from "never" (1 point) to "very often" (4 points). A higher combined score indicates a parenting style that was adopted more frequently. For our analytical sample, the Cronbach' s alpha was 0.827 (Bootstrap 95\% CI: 0.816-0.836).

\section{Impulsivity}

The Barratt Impulsiveness Scale (BIS) was used to evaluate impulsivity in participants. The BIS contains 30 items and three subscales, which assess impulsive planning, motor impulsiveness, and cognitive impulsiveness [25]. Each item can be scored from 1 to 5 based on a five-point scale. The total weighted score for the BIS ranges from 0 to 100, with a higher score indicating greater impulsivity. For our analytical sample, the Cronbach's alpha was 0.919 (Bootstrap 95\% CI: 0.915-0.923).

\section{Statistical analysis}

Descriptive analyses were used to delineate the participants' distributional characteristics. Based on univariate analysis, multivariate logistic regression models were developed to measure the adjusted associations between parenting styles, impulsivity, and SH. The possible mediation via impulsivity was evaluated using path analysis.
All statistical analyses were performed using $\mathrm{R}$ software (Version 3.6.2, The R Foundation for Statistical Computing, Vienna, Austria). In survey studies, especially those that employ a cluster sampling design, an intercorrelation between the participants may exist. Therefore, we utilized survey packages to control for this possible unequal sampling probability. For all analyses, the significance level was set as a two-tailed $p$-value less than 0.05 .

\section{Results}

General features of study participants

Among all 3146 participants, 1480 reported SH behaviors, with a lifetime reported SH prevalence of $47.0 \%$ (95\% CI: $36.3-58.0 \%$ ); the median of the BIS was 41.67 (inter-quartiles range, IQR: 10.84); the median values for paternal parenting styles were 7 (rejection, IQR: 3), 15 (emotional warmth, IQR: 8), and 16 (over-protection, IQR: 4), whereas the median values for maternal parenting styles were 8 (rejection, IQR: 3), 14 (emotional warmth, IQR: 7), and 17 (over-protection, IQR: 4).

\section{SH behaviors, parenting styles, and impulsivity}

For a better understanding of the results, we reversed the score of emotional warmth. Therefore, after reversion, a higher score indicated that an emotional warmth parenting style was adopted less frequently. The median of impulsivity (39.17) was used as the cut-off. After controlling for possible covariates, impulsivity was significantly associated with an increased occurrence of $\mathrm{SH}$ $(\mathrm{OR}=2.07,95 \% \mathrm{CI}: 1.75-2.44)$. For parenting styles, the results of the multivariate logistic regression models revealed the following: less emotional warmth from the father $(\mathrm{OR}=1.05,95 \%$ CI 1.02-1.09), maternal overprotection $(\mathrm{OR}=1.08,95 \%$ CI $1.02-1.14)$, and rejection $(\mathrm{OR}=1.09,95 \%$ CI 1.01-1.07) were associated with $\mathrm{SH}$ (Table 2).

\section{Path analysis}

Based on the results of the multivariate logistic regression models, we constructed an initial hypothesized path framework for paternal and maternal parenting styles. This path model achieved ideal fitting: The Root Mean Square Error of Approximation (RMSEA) was 0.001, and the Goodness-of-Fit Index (GFI) was 0.998. As we expected, impulsivity played a mediating role, as suggested by the model. However, only two paths (maternal rejection and over-protection) were statistically significant. Based on the standardized correlation coefficients shown in Fig. 1, the direct association between parenting styles and $\mathrm{SH}$ was 0.218 , and the indirect association mediated via impulsivity was 0.067 , accounting for $23.43 \%$ of the total association (Fig. 1). Further details regarding the bootstrap CIs for the indirect paths from parenting 
Table 2 Univariate and multivariable Logistic regression models fitting results for $\mathrm{SH}$

\begin{tabular}{|c|c|c|c|c|}
\hline \multirow[t]{2}{*}{ Covariates } & Univariate & Mutilvariable1 & Mutilvariable2 & Mutilvariable3 \\
\hline & OR $(95 \% \mathrm{Cl})$ & OR $(95 \% \mathrm{Cl})$ & OR $(95 \% \mathrm{Cl})$ & OR $(95 \% \mathrm{Cl})$ \\
\hline Age $(+1$ year $)$ & $1.27(1.18,1.37)$ & $1.09(0.90,1.32)$ & $1.12(0.94,1.33)$ & $1.10(0.91,1.33)$ \\
\hline Sex: Girls (Ref: Boys) & $1.38(1.24,1.54)$ & $1.44(1.17,1.78)$ & $1.40(1.13,1.74)$ & $1.42(1.14,1.76)$ \\
\hline \multicolumn{5}{|l|}{ Grade (Ref: Primary school) } \\
\hline Junior high school & $2.38(1.32,4.31)$ & $1.94(0.86,4.37)$ & $1.90(0.90,4.02)$ & $2.01(0.88,4.59)$ \\
\hline Senior high school & $3.47(2.21,5.45)$ & $2.48(0.94,6.57)$ & $2.27(0.95,5.42)$ & $1.11(1.00,1.23)$ \\
\hline Ethnicity (Ref: Other) & $1.03(0.81,1.32)$ & & & \\
\hline \multicolumn{5}{|l|}{ Father's education level (Ref: Elementary and below) } \\
\hline Junior high school above & $0.79(0.58,1.07)$ & & & \\
\hline \multicolumn{5}{|l|}{ Mother's education level (Ref: Elementary and below) } \\
\hline Junior high school above & $0.70(0.55,0.90)$ & $1.09(0.97,1.22)$ & $1.10(0.98,1.23)$ & $1.11(1.00,1.23)$ \\
\hline Father's age ( +5 years $)$ & $1.18(1.11,1.25)$ & $0.96(0.87,1.07)$ & $0.95(0.85,1.06)$ & $0.96(0.86,1.06)$ \\
\hline Mother's age ( +5 years) & $1.21(1.10,1.33)$ & $1.07(0.94,1.22)$ & $1.07(0.93,1.23)$ & $1.09(0.95,1.26)$ \\
\hline \multicolumn{5}{|l|}{ Impulsivity (Ref: Combined score < 39.17) } \\
\hline High (Combined score $>=39.17$ ) & $3.34(2.84-3.92)$ & $2.16(1.82,2.55)$ & $2.16(1.82,2.56)$ & $2.07(1.75,2.44)$ \\
\hline \multicolumn{5}{|l|}{ Parenting style } \\
\hline Father's Rejection (Combined score +1 ) & $1.20(1.14-1.26)$ & $1.13(1.07,1.20)$ & & $1.06(0.97,1.15)$ \\
\hline Father's Emotional Warmth (Combined score +1 ) & $1.08(1.06-1.10)$ & $1.05(1.03,1.07)$ & & $1.05(1.02,1.09)$ \\
\hline Father's Over-protection (Combined score+ 1) & $1.12(1.10-1.16)$ & $1.07(1.03,1.11)$ & & $1.01(0.93,1.09)$ \\
\hline Mother's Rejection (Combined score +1 ) & $1.22(1.17-1.26)$ & & $1.13(1.08,1.19)$ & $1.09(1.01,1.17)$ \\
\hline Mother's Emotional Warmth (Combined score +1 ) & $1.08(1.07-1.09)$ & & $1.05(1.02,1.07)$ & $1.00(0.96,1.03)$ \\
\hline Mother's Over-protection (Combined score +1 ) & $1.13(1.11-1.15)$ & & $1.08(1.05,1.11)$ & $1.08(1.02,1.14)$ \\
\hline
\end{tabular}

styles to $\mathrm{SH}$ are provided in the supplementary materials (Table S1).

Among individuals who self-harm, a significant association is observed between suicidal behaviors and the repetition and severity of $\mathrm{SH}$. A such, we performed an additional subgroup analysis in $1480 \mathrm{SH}$ adolescents, in an effort to explore impulsivity as a mediator in the association between parenting styles and $\mathrm{SH}$ repetition and $\mathrm{SH}$ severity. However, only non-significant associations were observed (Fig. 2).

\section{Discussion}

In the current study, based on the results from a large sample population of Chinese children and adolescents, we found that the prevalence of lifetime $\mathrm{SH}$ was $47.0 \%$, which was much higher than a pooled estimation of

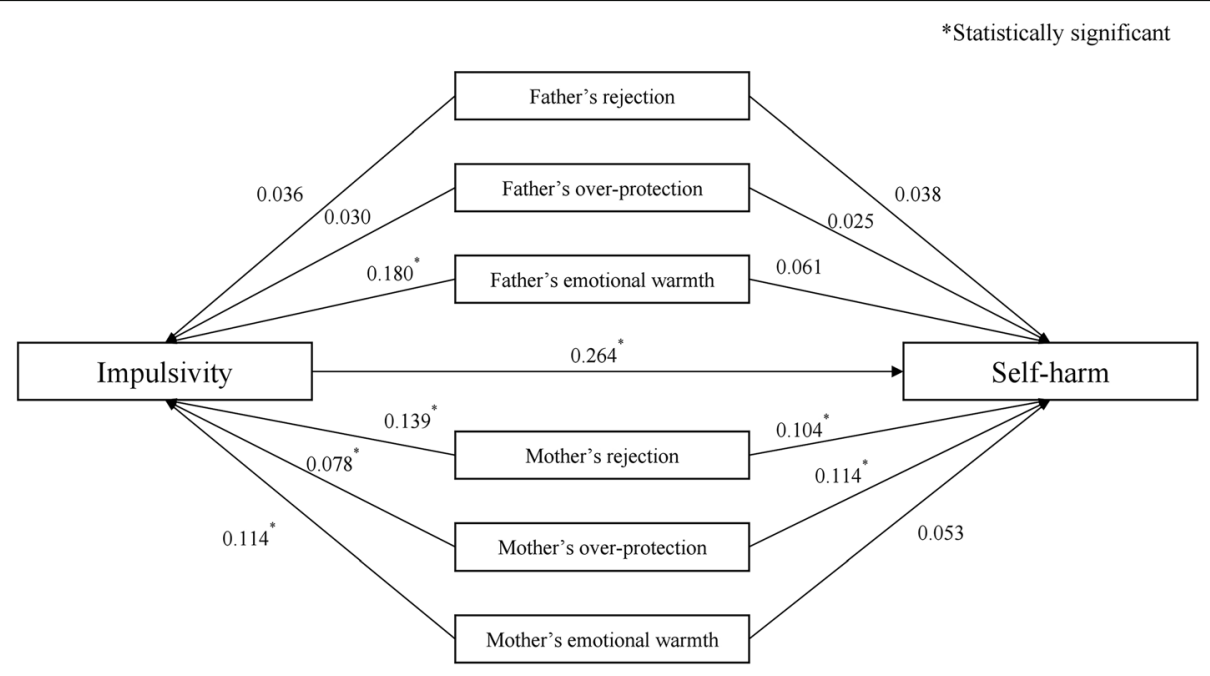

Fig. 1 Path model for father and mother's parenting-SH. Impulsivity and SH were adjusted for: age, sex and grade 


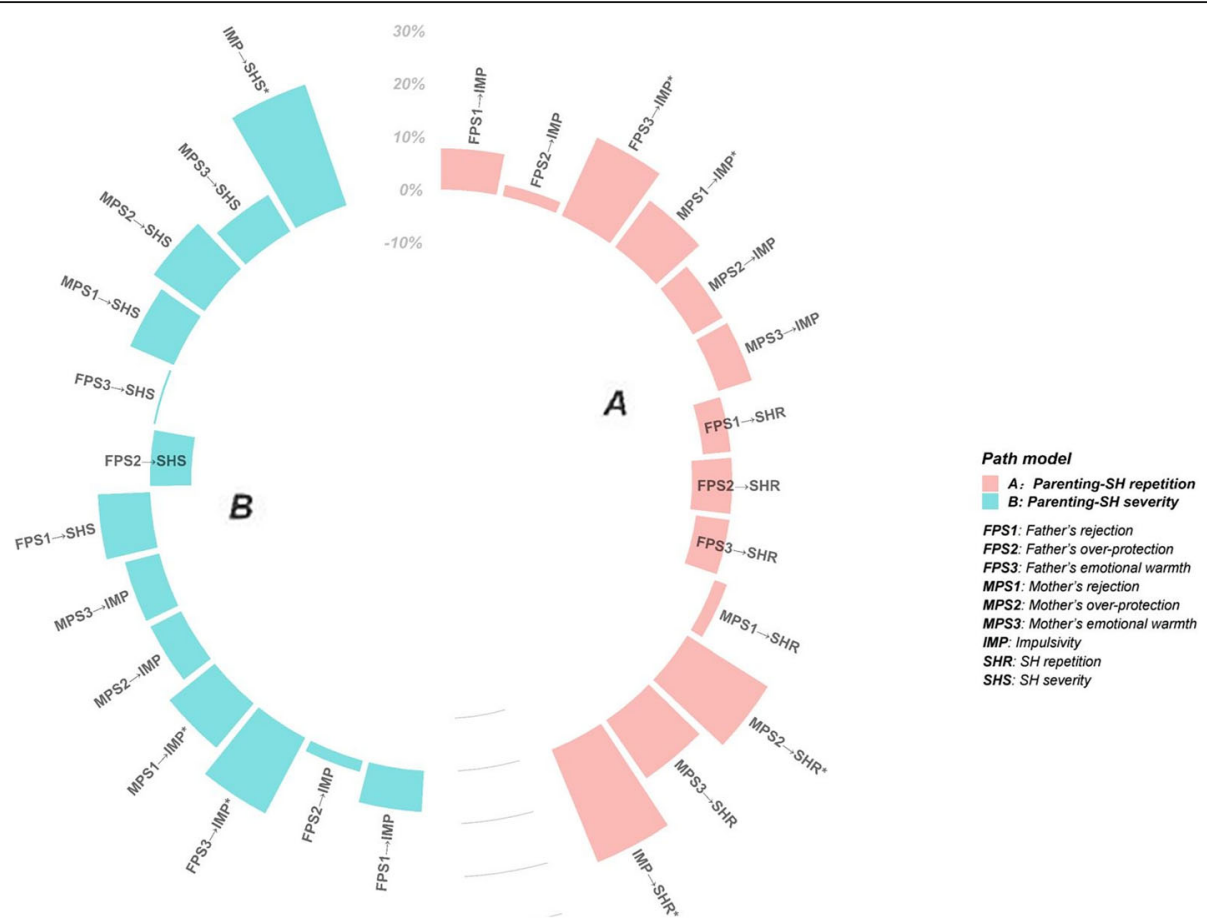

Fig. 2 Mediation of impulsivity in the associations between parenting styles and SH repetition, SH severity. FPS1: Father's rejection; FPS2: Father's over-protection; FPS3: Father's emotional warmth; MPS1: Mother's rejection; MPS2: Mother's over-protection; MPS3: Mother's emotional warmth; IMP: Impulsivity; SHR: SH repetition; SHS: SH severity

22.4\% among Chinese adolescents involved in the aforementioned meta-analysis [5]. The utilization of different SH instruments may largely explain this discrepancy: In the current study, we used MASHS to measure lifetime $\mathrm{SH}$ in the participants, whereas in the meta-analysis, most of the studies included applied short answer questions (SAQ) to evaluate $\mathrm{SH}$ behavior over a period of 6 months or 12 months. Moreover, the age distribution of the study participants differed. The current study included children and adolescents aged between 10 and 17 years old, whereas all of the participants in the metaanalysis were middle school and high school students.

Based on the results of the analysis, we found that less emotional warmth from the father, maternal overprotection, and rejection were significantly associated with $\mathrm{SH}$. This conclusion was in line with two previous studies, which suggested that adverse parenting styles were risk factors of $\mathrm{SH}$ and suicidal behaviors among a representative sample of 3653 Chinese adolescents [12, 26]. Parental over-protection and rejection can take the form of a stricter attitude and a higher level of control, and they have a negative effect on a child's confidence and independence, which may in turn lead to mental health issues [27]. For instance, a higher level of parental control could predict depression and anxiety among adolescents $[28,29]$. Due to cultural differences, Chinese parenting styles are distinct from those of western countries: Chinese parents, especially mothers, are more inclined to adopt over-protective parenting styles, which derive from traditional ideology, such as Confucianism [30]. A classic model of harsh maternal parenting in China is that of the "tiger mother", which generally describes mothers who exercise excessive control and harsh discipline towards their children [31]. A longitudinal study revealed that tiger parenting is associated with high academic pressure, depression, and a sense of alienation, all of which were identified as contributing factors in SH in youngsters [32]. Impulsivity, as a mediator of $\mathrm{SH}$, was only observed in the case of maternal over-protection. Therefore, with respect to adolescents who reported experiences of a harsh maternal parenting style, it is reasonable to suggest that intervention measures aimed at reducing impulsivity may achieve a better effect in the area of SH prevention and control. Another reasonable explanation concerns the way in which strict and harsh parenting, such as over-protection and rejection, may hinder the development of proper impulse controls in adolescents: Longitudinal evidence found higher levels of reported impulsivity among young people who experienced parental coercion [33].

After controlling for potential confounding factors, the hypothesized path model achieved ideal compatibility with our data, and it suggested that impulsivity was a meaningful mediator in the association between 
parenting styles and SH. Impulsivity is widely associated with many adolescent risk behaviors, especially SH [14]. Existing studies showed that adolescents who had engaged in SH generally reported a higher impulsivity level [34]. A longitudinal study revealed that the association between impulsivity and SH may be reciprocal, such that a higher level of impulsivity may lead to an increased risk of $\mathrm{SH}$, whereas more frequent $\mathrm{SH}$ behaviors may exacerbate tendencies towards impulsivity [14]. Some established models of impulsivity, such as the UPPS-P model and the Barratt model, suggested that individuals who reported $\mathrm{SH}$ were more inclined to act impulsively when experiencing negative emotions or events [14, 3537]. Another possible theory is that impulsivity may increase the likelihood of $\mathrm{SH}$ behavior by reinforcing the processes involved in $\mathrm{SH}$ ideation or thought: In their previous study, Madge et al. identified a series of prominent dose-response associations between cognitive impulsivity and $\mathrm{SH}$ ideation, $\mathrm{SH}$ occurrence, and $\mathrm{SH}$ events [38].

Impulsivity, as a personality trait, is closely associated with parenting styles. Parenting styles influence a child's development in the form of behaviors and personalities. Adverse parenting styles may lead to early maladaptive schemas (EMS) which begin to form in early childhood. Such schemas may have a long-lasting adverse effect that persists into adulthood, contributing to the development of affective and personality disorders [10, 39-41]. Shu et al. reported that parental rearing patterns, particularly rejection and over-protection, were predictors of an impulsive personality [18]. Considering all of the above, it is reasonable to identify impulsivity as a significant mediator in the association between parenting styles and $\mathrm{SH}$. With the exception of direct interventions aimed at nurturing positive parenting styles, this likely mediation factor also highlights the need to design and implement impulsivity-centered intervention measures, in an effort to curb parenting styles that contribute to the incidence of $\mathrm{SH}$ in adolescents. In fact, some promising behavior management procedures, such as the Good Behavior Game (GBG), could be incorporated into coping strategies that are designed to manage impulsivity or other disruptive behaviors [42]. Nevertheless, the performance of the GBG should be meticulously evaluated before implementation.

Some limitations of the current study should be noted. First, this study employed a cross-sectional design, which means that it is not possible to make causal inferences. Moreover, the sample in this study included participants from a locality in southwest China. Therefore, the generalization of the results to the wider Chinese adolescent population should be made with caution. Future studies should be carried out among a larger and more representative Chinese adolescent population. Finally, we relied on the self-report method to collect the survey data. As such, it is possible that the data may be affected by information bias. Studies which utilize multiple reporting sources (such as parents and relatives) should be considered.

Despite all of these limitations, our study adopted a novel approach to investigating impulsivity as a mediator in the association between parenting styles and $\mathrm{SH}$ among Chinese adolescents. Our major findings can contribute to furthering an understanding of the complicated relationship between parenting styles and $\mathrm{SH}$. Future studies with prospective designs are needed to corroborate our major findings.

\section{Conclusion}

This population-based study employed a cross-sectional design to examine parenting styles including less paternal emotional warmth, maternal over-protection, and rejection, which were significantly associated with $\mathrm{SH}$, and impulsivity was identified as a clear mediator in the association between parenting styles and SH. Our major findings suggest that, for Chinese adolescents who experience a harsher maternal parenting style, impulsivitycentered intervention measures might be effective in reducing parenting-style-related $\mathrm{SH}$.

\section{Supplementary Information}

The online version contains supplementary material available at https://doi. org/10.1186/s12889-021-10386-8.

Additional file 1: Table S1. Bootstrap confidence intervals for indirect paths from parenting styles to $\mathrm{SH}$.

\section{Abbreviations}

SH: Self-harm; MASHS: The Modified Version of Adolescents Self-Harm Scale; S-EMBU-C: The Chinese Version of the Short-Egna Minnen Barndoms Uppfostran; BIS: Barratt Impulsiveness Scale; Cl: Confidence interval; SE: Standard error; IQR: Interquartile range; OR: Odds ratio; RMSEA: Root mean square error of approximation; GFI: Goodness-of-fit index

\section{Acknowledgments \\ None}

\section{Authors' contributions}

YX and $J L$ designed the study. DF, DAR, RW, YC, XH, TW, and XX carried out the data collection, HR and $Y X$ performed data analysis, HR prepared the draft manuscript, YX critically revised the manuscript. All authors critically revised the manuscript for important intellectual content. The author(s) read and approved the final manuscript.

\section{Funding}

The study was supported by National Natural Science Foundation of China [No. 82060601], Yunnan Applied Basic Research Projects-Kunming Medical University Union Foundation [No. 2018FE001(-132)], Scientific Research Fund Project of Yunnan Provincial Department of Education [No. 2018JS198], NHC Key Laboratory of Drug Addiction Medicine [No. 2020DAMARA-006], Scientific Research Fund Project of Yunnan Provincial Department of Education [No. 2020Y116], Top Young Talents of Yunnan Ten Thousand Talents Plan [No. YNWR-QNBJ-2018-286], and the Innovative Research Team of Yunnan Province [No. 202005AE160002]. 


\section{Availability of data and materials}

The datasets analyzed during the current study are available from the corresponding author upon reasonable request.

\section{Ethics approval and consent to participate}

This study was approved by the Ethics Review Board of Kunming Medical University. In addition, the participants or their legal guardians or teachers provided their written informed consent. In the case of boarding students, written informed consent was obtained from teachers, and this was also approved by the institutional review board prior to the commencement of the study. For day students, written informed consent was obtained from their parents or legal guardians.

\section{Consent for publication}

Not applicable.

\section{Competing interests}

The authors declare that they have no competing interests.

\section{Author details}

'Department of Epidemiology and Health Statistics, School of Public Health, Kunming Medical University, Kunming, Yunnan, China. ${ }^{2}$ Psychiatric Department, First Affiliated Hospital of Kunming Medical University, Kunming, Yunnan, China. ${ }^{3}$ Lincang Psychiatric Hospital, Lincang, Yunnan, China. ${ }^{4} \mathrm{NHC}$ Key Laboratory of Drug Addiction Medicine, The First Affiliated Hospital of Kunming Medical University, Kunming, China.

\section{Received: 12 September 2020 Accepted: 3 February 2021}

\section{Published online: 10 February 2021}

\section{References}

1. Hawton K, Hall S, Simkin S, Bale L, Bond A, Codd S, Stewart A. Deliberate self-harm in adolescents: a study of characteristics and trends in Oxford, 1990-2000. J Child Psychol Psychiatry. 2003;44(8):1191-8.

2. Xiao Y, He L, Chang W, Zhang S, Wang R, Chen X, Li X, Wang Z, Risch HA. Self-harm behaviors, suicidal ideation, and associated factors among rural left-behind children in West China. Ann Epidemiol. 2020:42:42-9.

3. Xiao Y, Chen Y, Meng Q, Tian X, He L, Yu Z, Wang Y. Suicide ideation and suicide plan in Chinese left-behind children: prevalence and associated factors. J Affect Disord. 2019;257:662-8.

4. Swannell SV, Martin GE, Page A, Hasking P, St John NJ. Prevalence of nonsuicidal self-injury in nonclinical samples: systematic review, MetaAnalysis and Meta-Regression. Suicide Life-Threat Behav. 2014;44(3):273-303.

5. Lang J, Yao Y. Prevalence of nonsuicidal self-injury in Chinese middle school and high school students: a meta-analysis. Medicine. 2018;97(42):e12916.

6. Hawton K, Saunders KEA, O'Connor RC. Self-harm and suicide in adolescents. Lancet. 2012;379(9834):2373-82.

7. Darling N, Steinberg L. Parenting style as context: an integrative model. Psychol Bull. 1993;113:487-96.

8. Leung CL, Kwok SY, Ling CC. An integrated model of suicidal ideation in transcultural populations of Chinese adolescents. Community Ment Health J. 2016;52(5):574-81.

9. Huang $X Q$, Zhang HM, Li MC, Wang JA, Zhang Y, Tao R. Mental health, personality, and parental rearing styles of adolescents with internet addiction disorder. Cyberpsychology Behav Soc Netw. 2010;13(4):401-6.

10. Shute R, Maud M, McLachlan A. The relationship of recalled adverse parenting styles with maladaptive schemas, trait anger, and symptoms of depression and anxiety. J Affect Disord. 2019;259:337-48.

11. Martin J, Bureau JF, Yurkowski K, Lafontaine MF, Cloutier P. Heterogeneity of relational backgrounds is associated with variation in non-suicidal selfinjurious behavior. J Abnorm Child Psychol. 2016:44(3):511-22.

12. Liu Y, Xiao Y, Ran H, He X, Jiang L, Wang T, Yang RX, Xu X, Yang G, Lu J. Association between parenting and non-suicidal self-injury among adolescents in Yunnan, China: a cross-sectional survey. PeerJ. 2020;8:e10493.

13. Moeller FG, Barratt ES, Dougherty DM, Schmitz JM, Swann AC. Psychiatric aspects of impulsivity. Am J Psychiat. 2001;158(11):1783-93.

14. Hamza CA, Willoughby T. Impulsivity and nonsuicidal self-injury. A longitudinal examination among emerging adults. J Adolesc. 2019;75:37-46.

15. Curry I, Luk JW, Trim RS, Hopfer CJ, Hewitt JK, Stallings MC, Brown SA, Wall TL. Impulsivity dimensions and risky sex behaviors in an at-risk Young adult sample. Arch Sex Behav. 2018;47(2):529-36.
16. Mann JJ, Arango VA, Avenevoli S, Brent DA, Champagne FA, Clayton P, Currier D, Dougherty DM, Haghighi F, Hodge SE, et al. Candidate Endophenotypes for genetic studies of suicidal behavior. Biol Psychiatry. 2009:65(7):556-63.

17. McHugh CM, Lee RSC, Hermens DF, Corderoy A, Large M, Hickie IB. Impulsivity in the self-harm and suicidal behavior of young people: a systematic review and meta-analysis. J Psychiatr Res. 2019;116:51-60.

18. Shu E, Deng Y, Yuan H, Guan B. The relationship of impulsive personality and parental rearing patterns in junior middle school students. Chin J Behav Med Brain Sci. 2011;20(06):552-4.

19. Somer $\mathrm{E}$, Ginzburg K, Kramer $\mathrm{L}$. The role of impulsivity in the association between childhood trauma and dissociative psychopathology: mediation versus moderation. Psychiatry Res. 2012;196(1):133-7.

20. Arens AM, Gaher RM, Simons JS. Child maltreatment and deliberate selfharm among college students: testing mediation and moderation models for impulsivity. Am J Orthop. 2012;82(3):328-37.

21. Mishara BL. Conceptions of death and suicide in children ages 6-12 and their implications for suicide prevention. Suicide Life Threat Behav. 1999; 29(2):105-18.

22. Ran H, Cai L, He X, Jiang L, Wang T, Yang R, Xu X, Lu J, Xiao Y. Resilience mediates the association between school bullying victimization and selfharm in Chinese adolescents. J Affect Disord. 2020;277:115-20.

23. Feng $Y$. The relation of adolescents' self-harm behaviors, Individual Emotion Characteristics and Family Environment Factor. master. Wuhan: Central China Norm Univ; 2008. (In Chinese)

24. Jiang J. The preliminary revision of Short-Egna Minnen Barndoms Uppfostran-Chinese. Psychol Dev Educ. 2010;1:94-9.

25. Li X, Fei L, Xu D, Zhang Y, Yang S, Tong Y, Wang Z, Niu Y. Reliability and validity of an adapted Chinese version of Barratt impulsiveness scale. Chin Ment Health J. 2011;25(8):610-5 (In Chinese).

26. Chen Z, Wang Y, Chen L, Wang J, Jing Y, Yao J. Self-injurious behavior among college students and its association with parental rearing styles. Chin J School Health. 2019;40(4):546-9 (In Chinese).

27. Bai Y, Cui D, Zheng H, Xu Y, Zhu J, Wu Y, Shen H, Du Y. The correlation study between adolescent bipolar disorder and parental rearing pattern. China J Health Psychol. 2020;28(10):1441-4. (In Chinese).

28. Barber BK, Olsen JE, Shagle SC. Associations between parental psychological and behavioral control and youth internalized and externalized behaviors. Child Dev. 1994;65(4):1120-36.

29. Sun L, Tian W, Bian Y. Effect of adolescent depression and anxiety on the development tendency of parental psychological control: a 3 years followup study. Chin J Clin Psychol. 2018;26(4):730-5.

30. Zhang W, Wei X, Ji L, Chen L, Deater-Deckard K. Reconsidering parenting in Chinese culture: subtypes, stability, and change of maternal parenting style during early adolescence. J Youth Adolesc. 2017;46(5):1117-36.

31. Chua A. Battle hymn of the tiger mother: Bloomsbury publishing; 2011.

32. Kim SY, Wang Y, Orozco-Lapray D, Shen Y, Murtuza M. Does "Tiger parenting" exist? Parenting profiles of Chinese Americans and adolescent developmental outcomes. Asian Am J Psychol. 2013;4(1):7-18.

33. Rueth JE, Otterpohl N, Wild E. Influence of parenting behavior on psychosocial adjustment in early adolescence: mediated by anger regulation and moderated by gender. Soc Dev. 2017;26(1):40-59.

34. Mo J, Wang C, Niu X, Jia X, Liu T, Lin L. The relationship between impulsivity and self-injury in Chinese undergraduates: the chain mediating role of stressful life events and negative affect. J Affect Disord. 2019;256:259-66.

35. Maxfield BL, Pepper CM. Impulsivity and response latency in non-suicidal self-injury: the role of negative urgency in emotion regulation. Psychiatr $\mathrm{Q}$. 2018;89(2):417-26.

36. Taylor J, Peterson CM, Fischer S. Motivations for self-injury, affect, and impulsivity: a comparison of individuals with current self-injury to individuals with a history of self-injury. Suicide Life Threat Behav. 2012;42(6): 602-13.

37. Glenn CR, Klonsky ED. A multimethod analysis of impulsivity in nonsuicidal self-injury. Personal Disord. 2010;1(1):67-75.

38. Madge N, Hawton K, McMahon EM, Corcoran P, De Leo D, de Wilde EJ, Fekete S, van Heeringen K, Ystgaard M, Arensman E. Psychological characteristics, stressful life events and deliberate self-harm: findings from the Child \& Adolescent Self-harm in Europe (CASE) study. Eur Child Adolesc Psychiatry. 2011;20(10):499-508.

39. Basso LA, Fortes AB, Maia CPE, Steinhorst E, Wainer R. The effects of parental rearing styles and early maladaptive schemas in the development of 
personality: a systematic review. Trends Psychiatr Psychother. 2019;41(3): 301-13.

40. Young JE, Weinberger AD, Beck AT. Cognitive therapy for depression. In: Barlow DH, editor. Clinical handbook of psychological disorders: a step-bystep treatment manual. New York: The Guilford Press; 2001. p. 264-308.

41. Young J. Cognitive therapy for personality disorders: a schema focused approach. Professional Resource Press/Professional Resource Exchange; 1990.

42. Musci RJ, Bradshaw CP, Maher B, Uhl GR, Kellam SG, lalongo NS. Reducing aggression and impulsivity through school-based prevention programs: a gene by intervention interaction. Prev Sci. 2014;15(6):831-40.

\section{Publisher's Note}

Springer Nature remains neutral with regard to jurisdictional claims in published maps and institutional affiliations.

Ready to submit your research? Choose BMC and benefit from:

- fast, convenient online submission

- thorough peer review by experienced researchers in your field

- rapid publication on acceptance

- support for research data, including large and complex data types

- gold Open Access which fosters wider collaboration and increased citations

- maximum visibility for your research: over $100 \mathrm{M}$ website views per year

At BMC, research is always in progress.

Learn more biomedcentral.com/submissions 